\title{
Maha Badr, La connaissance productive du réel dans la poésie de Georges Schehadé
}

\section{Claudia Mansueto et [claudia mansueto]}

\section{(2) OpenEdition}

1 Journals

\section{Édition électronique}

URL : http://journals.openedition.org/studifrancesi/6474

DOI : 10.4000/studifrancesi.6474

ISSN : 2421-5856

Éditeur

Rosenberg \& Sellier

\section{Édition imprimée}

Date de publication : 1 novembre 2010

Pagination : 604-605

ISSN : 0039-2944

\section{Référence électronique}

Claudia Mansueto et [claudia mansueto], « Maha Badr, La connaissance productive du réel dans la poésie de Georges Schehadé », Studi Francesi [En ligne], 162 (LIV | III) | 2010, mis en ligne le 30 novembre 2015, consulté le 12 janvier 2021. URL : http://journals.openedition.org/studifrancesi/6474 ; DOI : https:// doi.org/10.4000/studifrancesi.6474

Ce document a été généré automatiquement le 12 janvier 2021.

\section{(c)}

Studi Francesi è distribuita con Licenza Creative Commons Attribuzione - Non commerciale - Non opere derivate 4.0 Internazionale. 


\title{
Maha Badr, La connaissance productive du réel dans la poésie de Georges Schehadé
}

\author{
Claudia Mansueto et [claudia mansueto]
}

\section{RÉFÉRENCE}

MAHA BADR, La connaissance productive du réel dans la poésie de Georges Schehadé, «Francofonia», primavera 2009, n. 56, pp. 37-52.

1 Maha Badr analyse le rôle que la réalité joue dans l'œuvre poétique de Georges Schehadé. Convaincu que le réel se manifeste à travers le lyrisme, le poète privilégie une écriture allusive pour favoriser une lecture oblique, qui aide à saisir l'épiphanie du réel qui caractérise sa poésie.

2 L'œuvre de Schehadé, selon Badr, nous permet de plonger dans un univers de contrastes, d'oppositions, d'identités duales et nous aide à réfléchir sur l'infinie galerie littéraire et cinématographique dominée par le charme du double et de l'Autre qui se cachent derrière le masque de l'apparence. L'allusion est à toute la littérature surréaliste, représentée par le manifeste inquiétant de l'œil coupé en deux de Buñuel, au symbolisme qui considère la réalité comme une simple succession d'images nécessaires pour voir au-delà, pour explorer d'autres mondes possibles et, enfin, à un auteur comme Perec qui considère le réel comme une sorte de miroir indispensable pour découvrir la vraie magie des objets qui se cache derrière le masque du banal. Maha Badr nous donne ici les instruments pour établir une relation authentique avec les poésies de Schehadé, la seule qui puisse faire vivre un texte, car le sens poétique, la valeur qu'on attribue aux mots, l'atmosphère qu'on crée autour d'une œuvre sont le résultat d'un travail de communion entre l'auteur et le lecteur. Quand Schehadé affirme que la magie poétique cache le réel, il invite le lecteur à s'efforcer de retrouver les traces du vrai au-delà de l'atmosphère dépaysante créée par l'auteur lui-même. En 
lisant l'étude de Maha Badr, on comprend comme toute l'œuvre de Schehadé n'est qu'une séduisante invitation à pénétrer l'univers poétique pour connaître son propre je. L'analyse des poésies de Schehadé amène Maha Badr à réfléchir, plus en général, sur l'une des caractéristiques de toute œuvre littéraire, qui est le résultat continu d'une cocréation: en effet, quand le lecteur entre dans un texte, il explore son monde intérieur à travers un long voyage finalisé à la construction de son identité, mais il contribue aussi à faire émerger l'un des innombrables sens dont toute œuvre est porteuse. 